\title{
Histopathology of stromal changes in tumor and tumor like lesions of breast using special stains
}

\author{
Reddy P. ${ }^{1}$, Sindhuja M. ${ }^{2}$ \\ ${ }^{1}$ Dr. Purushotham Reddy, Professor and HOD, ${ }^{2}$ Dr. Sindhuja M., MD Pathology; both authors are affilioated with \\ Department of Pathology, Karnataka Institute of Medical Sciences, Hubballi, Karnataka, India. \\ Corresponding Author: Dr. Sindhuja M., MD Pathology, Karnataka Institute of Medical Sciences, Hubballi, Karnataka, \\ India. E-mail: drsindhujam@gmail.com
}

\begin{abstract}
Background: The interplay between a tumor and its environment is exemplified by the morphological changes observed in the stroma of human breast cancer. Stromal changes in benign, premalignant and malignant lesions of breast helps in better understanding of disease process at the level of the tumor and host stromal reaction. Objectives- (1) To compare the stromal changes in benign, proliferative breast lesions and malignant breast lesion (2) To compare the stromal changes with grade of malignant breast lesions. Methodology: This was a one-year prospective study carried out in the department of Pathology KIMS, Hubballi, Karnataka, from January 2017 to December 2017. Excision biopsies and mastectomy specimens were collected in $10 \%$ buffered formalin and subjected to paraffin processing and embedding. Five-micron thick sections were cut and stained with H\&E and special histochemical stains namely Masson's Trichrome Stain (MTS) and Verhoeff's Van Gieson (VVG) were used to study collagen and elastin content respectively. Results: The study included 121 cases of excision biopsies and mastectomies. Benign tumors and tumor like lesions showed more collagenosis compared to malignant lesions, whereas malignant lesions showed more elastosis compared to benign lesions. Grade III malignant tumors showed more elastosis when compared to Grade II and Grade I tumors. Conclusion: Tumor stroma in breast has been neglected in many studies. Upcoming prevention, diagnostic and therapy strategies and studies should be carried in an unbiased way, allowing analysis of stromal component in addition to classical investigations of the epithelial cancer component.
\end{abstract}

Keywords: Breast stroma; Collagenosis, Elastosis

\section{Introduction}

The development of the breast is sensitive to interactions between the epithelium and stroma. Mammary gland is made up of both epithelium and stroma that communicate with each other through extracellular matrix. Breast cancer can be both induced and promoted by disrupting the communication between epithelium and stroma. The crosstalk between mammary epithelium and stroma is also important for the proper patterning and functioning of normal breast. Experimental evidence suggests that a reduction in signalling between any of the stromal cell types (fibroblasts, macrophages, endothelial cells and adipocytes) results in reduced or absent breast development. The epithelial-stromal interactions that occur in tumors are less well characterized but there is no doubt that there is expansion of the stroma and the epithelium during tumor development [1].

Manuscript received: $28^{\text {th }}$ August 2019 Reviewed: $7^{\text {th }}$ September 2019

Author Corrected: $14^{\text {th }}$ September 2019

Accepted for Publication: 17 $7^{\text {th }}$ September 2019
In carcinoma, the cellular organization is dramatically changed, and the stroma is extensively modified with extensive remodelling of extracellular matrix in the form of fibrosis and elastosis. A prominent feature of stromal reaction in most breast carcinoma is the presence of elastic tissue element, a process called elastosis [2].

The role of stroma as a mediator of normal mammary development, as well as a critical regulator of malignant conversion and progression in breast cancer is known. It is well established that stroma associated with normal mammary gland development is strikingly different from the stroma in a developed breast cancer[3]. Studies using a wide range of techniques, including stromal cell isolation, modification of stromal specific gene expression, recreation of specific microenvironment in tissue samples have demonstrated that stroma can promote cancer and that the expression patterns within the stroma can influence clinical outcome $[4,5]$.

Breast cancer is one of the most commonly diagnosed form of cancers. In spite of impressive advances made in 
Original Research Article

molecular biology, breast cancer still remains one of the most frequent malignancies, because of our lack of knowledge of what causes and promotes the disease.

Recognition of the important role of the stroma during the progression of breast cancer, leads to possible identification of new targets for the treatment of initial breast cancer lesions as well as prevention of recurrence.

Better understanding of the dynamic interactions between epithelium and stroma, and between cancer and stroma will help define the windows of opportunity in the stroma for cancer suppression and repression.

The present study is undertaken to emphasize the importance of stromal changes in tumor and tumor like lesions of breast, by studying the stromal changes in benign, proliferative breast lesions and malignant breast lesions and by comparing the stromal changes in different grades of malignant breast lesions.

\section{Materials and Methods}

Setting- The present study was done in a tertiary care hospital, in the Department of Pathology, Karnataka Institute of Medical Sciences, Hubballi.

Duration- The present study was done from January 2017 and December 2017 for a period of one year.

Type of study- This was a descriptive study

Sampling Method- This study was conducted on a total of 121 cases of tumor and tumor like lesions of breast received during the study period in Department of Pathology, Karnataka Institute of Medical Sciences, as per the inclusion and exclusion criteria.

Sample size calculation- A sample size of 99 was calculated by taking the prevalence of stromal changes as $54.5 \%$ (based on previous studies), absolute precision as $10 \%$, using the formula $n=4 P Q / d^{2}$

Inclusion criteria-1) All excision biopsies and mastectomy specimens

Exclusion criteria
1) Male breast specimens

2)Trucut biopsies / Core needle biopsies

3)Referral slides / blocks

Data collection- All excision biopsies and mastectomy specimens received in $10 \%$ formalin in the Department of Pathology, Karnataka Institute of Medical Sciences, Hubballi were studied for gross findings, histopathological and special stain findings. Clinical details were obtained from hospital records.

A minimum of 24 hours was allowed for fixation. Sections for the study were taken from tumor proper and normal appearing breast tissue. Additional sections were taken if any prominent desmoplastic change was observed grossly.

After routine processing and embedding of tissue sections in paraffin blocks, three sections of five microns thickness were cut from each paraffin block. One section was stained with Hematoxylin and Eosin and the other two sections were stained with Masson's Trichome stain and Verhoff's van Gieson stain respectively, for the identification and grading of stromal changes of collagen and elastin.

Data analysis- The collected data were entered in Microsoft Excel worksheet and analysed using SPSS. Statistical test like chi-square test was used and $\mathrm{p}<0.05$ was considered as statistically significant.

Ethical consideration and permission- Ethical clearance was obtained from the college authorities.

Grading system- Stromal changes were assessed using Masson's Trichrome stain and Verhoff's Van Gieson stain for collagen and elastin respectively. Results were interpreted as follows, (graded according to study conducted by Radhakrishnan et al [6])

Grade 0 - absent

Grade 1 - doubtful increase

Grade 2 - definite, but small increase

Grade 3 - conspicuous increase

Grade 4 - massive increase

\section{Results}

In the present study, a total of 121 cases were encountered which included 111 tumors $(91.73 \%)$ and 10 tumor like lesions (8.26\%). Among 111 tumors, 74 (66.66\%) were benign and 37 (33.33\%) cases were malignant.

Among 74 benign tumors, majority were fibroadenoma accounting to $91.89 \%$ ( 68 cases) followed by phyllodes, accounting to $6.75 \%$ ( 5 cases) and 1 case was adenomyoepithelioma.

There were a total of 37 malignant tumors, among which 36 were malignant epithelial tumors and one case was mesenchymal tumor. Among the 36 malignant epithelial tumors, 32 were infiltrating ductal carcinoma accounting to

Pathology Update: Tropical Journal of Pathology \& Microbiology Available online at: www.medresearch.in 664 | P a g e 


\section{Original Research Article}

$86.48 \%$ and other specialized variants like ILC, medullary carcinoma, mucinous carcinoma and papillary carcinoma accounted for one case each, Majority i.e 21 cases (58.33\%) were Grade II, followed by 11 cases $(30.55 \%)$ which were Grade III and 4 cases (11.11\%) were Grade I.

Among the 10 tumor like lesions, 8 cases were fibrocystic disease and 2 cases were sclerosing adenosis. Majority of the benign tumors and tumor like lesions were observed in third decade of life. Majority of the malignant tumors were observed between fifth and sixth decade of life.

Collagen estimation: In the present study, among 74 benign tumors, about $75.67 \%$ showed significant (grade $>=2$ ) collagenosis and among 10 cases of tumor like lesions 90\% showed significant (grade $>=2$ ) collagenosis, while 59.45\% of malignant tumors among 37 cases, showed significant collagenosis, as shown in Table 1.

Table-1: Table showing grade of collagenosis in benign, malignant and tumor like lesions

\begin{tabular}{|c|c|c|c|c|c|c|}
\hline $\begin{array}{c}\text { Grade of } \\
\text { collagen }\end{array}$ & $\begin{array}{c}\text { No. of Benign } \\
\text { lesions }\end{array}$ & Percentage & $\begin{array}{c}\text { No. of Tumor } \\
\text { like lesions }\end{array}$ & Percentage & $\begin{array}{c}\text { No. of } \\
\text { Malignant } \\
\text { lesions }\end{array}$ & Percentage \\
\hline 0 & 1 & 1.35 & 0 & 0 & 0 & 0 \\
\hline 1 & 17 & 22.97 & 1 & 10 & 15 & 40.54 \\
\hline 2 & 34 & 45.94 & 4 & 40 & 14 & 37.83 \\
\hline 3 & 18 & 24.32 & 4 & 40 & 8 & 21.62 \\
\hline 4 & 4 & 5.40 & 1 & 10 & 0 & 0 \\
\hline Total & $\mathbf{7 4}$ & $\mathbf{1 0 0}$ & $\mathbf{1 0}$ & $\mathbf{1 0 0}$ & $\mathbf{3 7}$ & $\mathbf{1 0 0}$ \\
\hline
\end{tabular}

Hence, Collagenosis appears to be the more prominent stromal reaction in benign and tumor like lesions when compared to malignant lesions ( $\mathrm{p}$ value $=0.043308$ )

Among 74 benign tumors, there were total of 68 fibroadenomas, out of which, 52 cases $(76.4 \%)$ showed significant (grade $>=2$ ), among which majority of them i.e 31 cases $(45.58 \%$ ) showed Grade 2 collagen. Among 5 cases of phyllodes tumor, 4 cases $(80 \%)$ showed significant collagen, majority of them $60 \%$ showing Grade 2 collagen. One case of Aden myoepithelioma included in the study, showed Grade 1 collagen.

There were 10 cases of tumor like lesions, which included 2 sclerosing adenosis and 8 fibrocystic disease. Both the cases of sclerosing adenosis showed significant (grade $>=2$ ) collagen, among which one case showed grade 3 and the other showed Grade 4 collagen (Figure 1) respectively. Among 8 cases of fibrocystic disease, significant collagenosis was observed in 7 cases $(87.50 \%)$, most of which $(50.0 \%)$ exhibiting Grade 2 collagen.

Among 32 cases of IDCs, $60.50 \%$ cases showed significant collagenosis, among which majority of them i.e 13 cases (40.62\%) showed Grade 2 collagen. Twelve cases showed Grade 1 collagen and seven cases showed Grade 3 collagen. One case of ILC, in the present study showed Grade 3 collagen, while 1 case of papillary carcinoma showed Grade 2 collagen. One case each of mucinous carcinoma, medullary carcinoma and fibrosarcoma, all showed Grade 1 collagen. Collagenosis appears to be more common feature only in IDCs and ILC, whereas in other specialised variants of malignant tumors collagenosis was not commonly observed.

Elastin estimation: Among 74 benign lesions, none of them showed significant (grade $>=2$ ) elastosis, similarly among 10 cases of tumor like lesions only $20 \%$ ( 2 cases) showed significant elastosis.

Among 37 malignant tumors, 22 cases (59.45\%) showed significant elastosis, among which majority of them i.e 19 cases (51.35\%) showed Grade 2 elastin, two cases showed Grade 3 elastin and one case showed Grade 4 elastin, as shown in Table 2.

Table-2: Table showing grade of elastosis in benign, malignant and tumor like lesions 
Original Research Article

\begin{tabular}{|c|c|c|c|c|c|c|}
\hline $\begin{array}{c}\text { Grade of } \\
\text { elastin }\end{array}$ & $\begin{array}{c}\text { No. of } \\
\text { Benign } \\
\text { lesions }\end{array}$ & Percentage & $\begin{array}{c}\text { No. of } \\
\text { Tumor like } \\
\text { lesions }\end{array}$ & Percentage & $\begin{array}{c}\text { No. of } \\
\text { Malignant } \\
\text { lesions }\end{array}$ & Percentage \\
\hline 0 & 73 & 98.64 & 7 & 70 & 3 & 8.10 \\
\hline 1 & 1 & 1.35 & 1 & 10 & 12 & 32.43 \\
\hline 2 & 0 & 0 & 2 & 20 & 19 & 51.35 \\
\hline 3 & 0 & 0 & 0 & 0 & 2 & 5.40 \\
\hline 4 & 0 & 0 & 0 & 0 & 1 & 2.70 \\
\hline Total & $\mathbf{7 4}$ & $\mathbf{1 0 0}$ & $\mathbf{1 0}$ & $\mathbf{1 0 0}$ & $\mathbf{3 7}$ & $\mathbf{1 0 0}$ \\
\hline
\end{tabular}

Pattern of elastosis observed were periductal, stromal and perivascular elastosis.

Hence, Elastosis appears to be the predominant stromal change in malignant lesions when compared to benign and tumor like lesions ( $\mathrm{p}$ value $=0.00001)$.

Among 32 IDCs, 65.62\% (21 cases) showed significant elastosis, among which majority of them (19 cases, 59.37\%) showed Grade 2 elastosis, one case showed Grade 3 elastosis (Figure 2) and one case showed Grade 4 elastosis (Figure 3 ). Among other types of malignant lesions, one case of ILC showed Grade 3 elastin. One case each of medullary carcinoma, mucinous carcinoma, papillary carcinoma and fibrosarcoma, all showed no significant elastosis. Elastosis appears to be the predominant stromal change only in IDCs and ILCs, while other specialised variants did not show elastosis.

There were 36 malignant epithelial tumors encountered in the present study, among which four were Grade I, twenty-one were Grade II and eleven were Grade III tumors. Among four Grade I tumors, none of them showed significant (grade >= 2) elastosis, all the four cases showed Grade 1 elastin content.

Among twenty-one Grade II tumors, 61.90\% showed significant elastosis, among which majority of them showed Grade 2 elastosis (Figure 4). Among eleven Grade III tumors, $81.81 \%$ showed significant elastosis, among which majority of them showed Grade 2 elastosis (Figure 5).

Overall, Grade 2 elastosis was the most common pattern, which is exhibited by Grade II and Grade III tumors (19 out of 36 cases).

However, when number of cases showing significant elastosis was compared between the different grades of tumor, $81.81 \%$ of grade III tumors, $61.90 \%$ of grade II tumors and none of the grade I tumors showed significant elastosis (Grade $>=2$ ) i.e (Grade III tumors > Grade II tumors > Grade I tumors), as shown in Table 3.

Table-3: Table showing relationship between degree of elastosis and the grade of tumor in malignant lesions

\begin{tabular}{|c|c|c|c|c|c|c|}
\hline \multirow{2}{*}{$\begin{array}{c}\text { Grade of } \\
\text { elastin }\end{array}$} & \multicolumn{7}{|c|}{\begin{tabular}{c} 
Grade of tumor \\
Grade I \\
\cline { 2 - 7 }
\end{tabular}} & Percent & $\begin{array}{c}\text { Grade II } \\
\text { (No. of cases) }\end{array}$ & Percent & $\begin{array}{c}\text { Grade III } \\
\text { (No. of cases) }\end{array}$ & Percent \\
\hline 0 & 0 & 0 & 2 & 9.52 & 0 & 0 \\
\hline 1 & 4 & 100 & 6 & 28.57 & 2 & 18.18 \\
\hline 2 & 0 & 0 & 11 & 52.38 & 8 & 72.72 \\
\hline 3 & 0 & 0 & 1 & 4.76 & 1 & 9.09 \\
\hline 4 & 0 & 0 & 1 & 4.76 & 0 & 0 \\
\hline Total & 4 & 100 & 21 & 100 & 11 & 100 \\
\hline
\end{tabular}

Hence elastosis appears to increase, as the grade of the tumor increased ( $p$ value $=0.0159)$ 


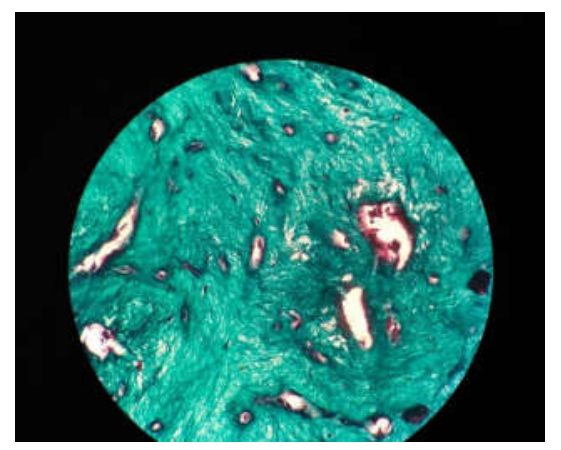

Original Research Article

Figure-1: Grade 4 collagen in a case of sclerosing adenosis (10x, MTS)

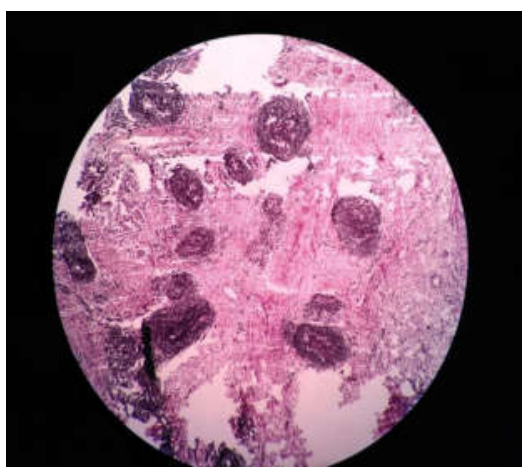

Figure-2: Microscopy of Grade 3 periductal elastosis in a case of Grade III IDC, showing jet black elastin fibres around malignant ducts (10x, VVG stain)

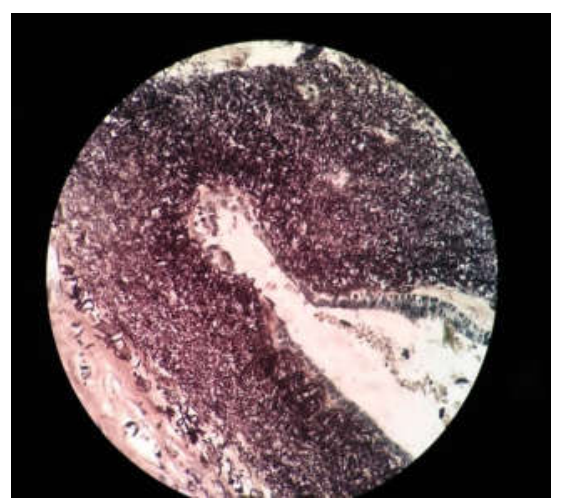

Figure-3: Microscopy of Grade 4 periductal elastosis in a case of Grade II IDC (40x, VVG stain)

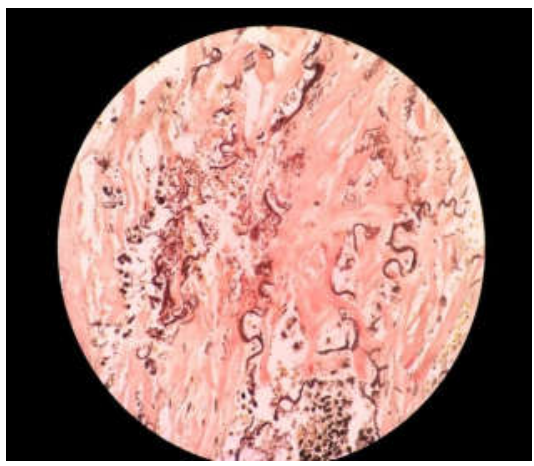

Figure 4: Microscopy of Grade 2 stromal elastosis - Grade II IDC (40x, VVG) 


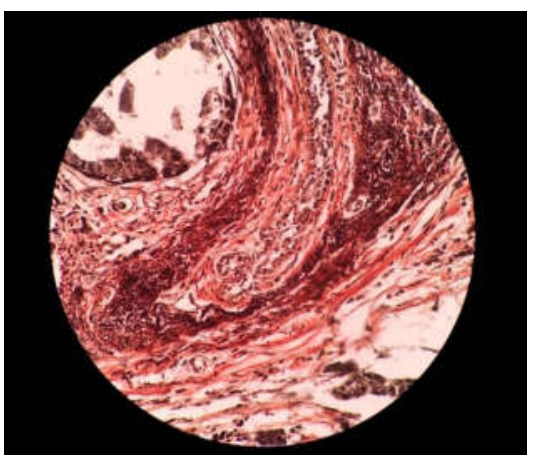

Original Research Article

Figure-5: Microscopy of Grade 2 elastosis in a case of Grade III IDC, periductal pattern (40x, VVG stain)

\section{Discussion}

In a normal mature breast, the duct system is invested by elastic tissue. It is present as a cuff of fibrillar elastic tissue in main lactiferous ducts, segmental ducts and their branches. At the level of ductules, elastic tissue ends. When the ductule enters the lobule, there is a complete absence of elastic tissue. The interlobular stroma contains only occasional elastic fibres. With menopause there occurs involution of lobules and ducts which involves loss of some or even most of elastic tissue in the walls of ducts. There is no increase in ductal elastic tissue with age or onset of menopause [7].

Ultrastructurally, surrounding the ducts and ductules of breast, the stroma is arranged in a series of alternating concentric layers, one layer by fibroblasts and the next layer by collagen bundles, granular material and occasional elastic fibres. The few elastic fibres were composed of central core of elastin surrounded by sparse microfibrils [8]. In carcinomas the amount of stroma varies in different sites. Its composition also ranges from fibroblastic to densely hyaline, and the stroma contains varying amounts of collagen, extracellular mucin, and elastic tissue. Often, the fibroblastic, or desmoplastic, reaction to the growth of malignant cells is the predominant feature of the tumor mass. Tumors with a large amount of dense hyaline stroma were previously termed scirrhous. In some carcinomas, the stroma is uniformly distributed, but in others the centre of the tumor is fibrotic and relatively acellular, with the malignant epithelial components seen mainly at the periphery [9].

Elastosis on gross specimens appear as 'yellow streaks' which was initially thought to be fatty degeneration [10]. There are two types of focal elastosis namely periductal and perivascular elastosis. Periductal elastosis is identified as increase in elastic cuff surrounding the ducts which appears as a broadened zone with increased density of elastic tissue. With florid elastosis, a very wide periductal band of jet-black tissue is seen in an elastin stained section [11]. Breast cancers are one of the highly complex tissues with malignant cells constituting only one of the many distinct cell types. Only a small proportion is represented by malignant cells. The remaining cells are often grouped under the term 'tumor associated stroma'. The tumor associated stroma includes fibroblasts, myofibroblasts, macrophages, immune cells, adipocytes and endothelial cells. The role of stroma in breast cancer pathogenesis has become an area of intense investigation due to mounting evidence demonstrating its ability to promote tumor development [13, 14].

Tumor progression is contributed by particular signalling molecules which are expressed by cancer associated fibroblasts (CAFs) and other cell types that are present in the stroma. While there are evidences that CAFs promote tumor growth, their origin remains unknown. CAFs and myofibroblasts can be derived from circulating fibrocytes. These fibrocytes are known to differentiate into myofibroblasts and have been identified within invasive ductal carcinomas as well as in DCIS lesions causing elastosis $[15,16,17,18]$. While many studies propose elastosis as a good prognostic factor, many other studies identify elastosis did not have much influence on prognosis. Yet other recent studies are focusing on tumor stroma trying to arrive at the possible role of tumor associated stroma in the progression of cancer [8, 11, 19, 21, 22-28].

In the present study of 121 cases of tumor and tumor like lesions of breast, collagenosis was found to be a prominent feature of benign and tumor like lesions when compared with malignant lesions ( $\mathrm{p}$ value -0.043308 , which was significant). Whereas, elastosis was found to be a predominant feature found in malignant lesions when compared to benign tumors and tumor like lesions ( $\mathrm{p}$ value -0.00001 , which was significant).

Prognosis could not be evaluated, as the follow up of cases were not done.

In present study, $75.6 \%$ of benign, $90 \%$ of tumor like lesions (TLL) and $35.6 \%$ of malignant cases showed significant 
Original Research Article

(grade of collagen $>=2$ ) collagenosis. In Pai et al [10], study, $86.4 \%$ of benign, $100 \%$ of TLLs and $84.1 \%$ malignant lesions showed significant collagenosis, as shown in Table 4.

Table-4: Table showing percentage of cases showing significant collagenosis in different lesions of breast in comparison with other studies.

\begin{tabular}{|c|c|c|}
\hline Lesions & Present study & Pai et al [10] \\
\hline Benign & $75.6 \%$ & $86.4 \%$ \\
\hline Malignant & $35.6 \%$ & $84.1 \%$ \\
\hline Tumor like lesions & $90 \%$ & $100 \%$ \\
\hline
\end{tabular}

The difference in collagenosis in malignant lesions of present study and Pai et al, study could possibly be due to inter observer variation or due to difference in the areas sampled to study collagen in malignant cases, as collagenosis and elastosis of stroma differs in different areas of the same breast.

In an ultrastructural study conducted by Martinez et al, cases of fibroadenoma and sclerosing adenosis showed prominent reduplication of ductular basement membrane. Surrounding the ductules, the stroma was predominantly composed of collagen fibres, fibroblasts, and a granular matrix. No elastic fibres were present [8].

H M Aiyer, et al in their study of diagnostic stromal histomorphology in fibroepithelial breast lesions, observed an increasing grade of stromal cellularity, pleomorphism, stromal overgrowth and mitotic index from the benign to the borderline and overtly malignant lesions [29].

In present study none of the benign tumors showed elastosis and $56.75 \%$ of malignant tumors showed significant elastosis, which is in concordance with Pai et al, study, where none of the benign lesions showed significant elastosis and $54.5 \%$ malignant lesions showed significant elastosis, as shown in Table 5.

Table-5: Table showing percentage of cases showing significant elastosis in different lesions of breast in comparison with other studies.

\begin{tabular}{|c|c|c|}
\hline Lesions & Present study & Pai et al [10] \\
\hline Benign & $0 \%$ & $0 \%$ \\
\hline Malignant & $56.75 \%$ & $54.5 \%$ \\
\hline Tumor like lesions & $20 \%$ & $0 \%$ \\
\hline
\end{tabular}

Among different histological types of malignant lesions, $66.66 \%$ of IDC and ILC combined, showed significant elastosis, which was slightly higher than the study done by Pai et al [10] and Azzopardi et al [11], whereas Bindu et al [12], encountered significant elastosis in $96.77 \%$ of cases.

In the present study as well as in the study done by Pai et al, and Bindu et al, there was no significant elastosis in medullary carcinoma, mucinous carcinoma and papillary carcinoma, whereas, Azzopardi et al, encountered 10\% of medullary carcinoma which showed significant elastosis, as shown in Table 6.

Table-6: Table showing significant elastosis in different histological types of malignant lesions in comparison with other studies

\begin{tabular}{|c|c|c|c|c|}
\hline \multirow{2}{*}{ Type of carcinoma } & \multicolumn{4}{|c|}{ Elastosis } \\
\cline { 2 - 5 } & Present study & Pai et al [10] & Azzopardi et al [11] & Bindu et al [12] \\
\hline IDC \& ILC & $66.66 \%$ & $54.5 \%$ & $56 \%$ & $96.77 \%$ \\
\hline Medullary & $0 \%$ & $0 \%$ & $10 \%$ & $0 \%$ \\
\hline Mucinous & $0 \%$ & $0 \%$ & $0 \%$ & $0 \%$ \\
\hline Papillary & $0 \%$ & $0 \%$ & $0 \%$ & - \\
\hline Miscellaneous & $0 \%$ & $0 \%$ & $0 \%$ & - \\
\hline
\end{tabular}

When pattern of elastosis was considered, stromal pattern of elastosis was found to be the predominant pattern in the present 


\section{Original Research Article}

study, whereas in Pai et al and Radhakrishnan et al studies, periductal was the predominant pattern. Perivascular pattern was the least common pattern observed in the present study and in other studies as well.

Out of 36 malignant epithelial tumors, Grade $>=$ 2elastosis was exhibited maximally by Grade II tumors i.e. $36.11 \%$ (13 out of 36 cases), which was consistent with Bindu et al study, where Grade $>=2$ elastosis was exhibited maximally by Grade II tumors i.e. $81.81 \%$ (54 out of 66 cases), as shown in Table 7.

Table-7: Table showing relationship of elastosis with grade of tumor in malignant epithelial tumors, in comparison with other studies.

\begin{tabular}{|c|c|c|c|c|c|c|}
\hline \multirow{2}{*}{$\begin{array}{c}\text { Degree of } \\
\text { elastosis }\end{array}$} & \multicolumn{2}{|c|}{ Grade I } & \multicolumn{2}{c|}{ Grade II } & \multicolumn{2}{c|}{ Grade III } \\
\cline { 2 - 7 } & $\begin{array}{c}\text { Present } \\
\text { study }\end{array}$ & Bindu et al & Present study & Bindu et al & Present study & $\begin{array}{c}\text { Bindu et al } \\
{[12]}\end{array}$ \\
\hline$<2$ & $4(11.11 \%)$ & $3(4.54 \%)$ & $8(22.22 \%)$ & $1(1.51 \%)$ & $2(5.55 \%)$ & $2(3.0 \%)$ \\
\hline$>=2$ & 0 & $3(4.54 \%)$ & $13(36.11 \%)$ & $54(81.81 \%)$ & $9(25.0 \%)$ & $3(4.54 \%)$ \\
\hline Total & $\mathbf{4 ( 1 1 . 1 1 \% )}$ & $\mathbf{6 ( 9 . 0 9 \% )}$ & $\mathbf{2 1 ( 5 8 . 3 3 \% )}$ & $\mathbf{5 5 ( 8 3 . 3 \% )}$ & $\mathbf{1 1 ( 3 0 . 5 5 \% )}$ & $\mathbf{5 ( 7 . 5 4 \% )}$ \\
\hline
\end{tabular}

However wide range of difference in the percentage of grade II tumors showing significant elastosis between the present study and Bindu et al, study was probably because of the difference in the number of cases included in the studies. It could also be due to difference in the time of presentation of the cases to the hospital, where stromal changes could change with the duration of disease or it could be due to difference in the areas sampled, where stromal changes differs in different areas of the same breast.

According to Shivas and Douglas [19], moderate degree of elastosis was found to be associated with maximum number of cases, a finding which was consistent with present study.

According to Fisher et al [20], moderate to marked degree of elastosis was maximally observed in Grade II tumors, which was again consistent with the present study.

In an ultrastructural study conducted by Martinez et al, all the IDCs examined had dense stroma which had four elements, like elastic fibres, collagen, connective tissue cells and ground substance. Elastic fibres were the most abundant among all. Collagen fibres were less abundant and were randomly mixed with elastic fibres. In between the collagen and elastic fibres and without any particular orientation, were elongated cells with fusiform nuclei with appearance of myofibroblasts [8].

Limitations of present study- The present study needs a long term followup for at least 5-10 years in all malignant cases to compare the degree of elastosis with its outcome.

\section{Conclusion}

In the present study, collagenosis was found to be expressed more by benign tumors and tumor like lesions of breast when compared to malignant lesions. Whereas, elastosis was found to be feature associated with malignant lesions when compared with benign lesions. Further, there was increase in elastosis, with increase in the grade of malignant tumor.

While many studies propose elastosis as a good prognostic factor, many other studies identify elastosis did not have much influence on prognosis. Yet other recent studies are focusing on tumor stroma trying to arrive at the possible role of tumor associated stroma in the progression of cancer. Thus, the area of tumor stroma and the stromal changes associated with breast cancer still remains a open field of research. Current therapies target mainly the cancer cells, however many cases come up with recurrences and distant metastases following treatment.

Given the supportive and instructive role of stroma in cancer progression, therapies tailored to both the stroma and epithelium may have more clinical efficacy in preventing recurrence and metastases.

\section{What this study adds to the existing knowledge?}

This study has shown that grade of elastosis increases 
with grade of tumor. Further studies on stromal molecular changes to predict invasion has promising future.

\section{Author's contributions}

- Dr. Purushotham Reddy: Conceptualized the study, senior author on the manuscript, helped with manuscript construction, data analysis and proofreading.

- Dr. Sindhuja Mani: Helped with data collection, analysis, manuscript construction and involved in submission of final report.

Findings: Nil; Conflict of Interest: None initiated

Permission from IRB: Yes

\section{Reference}

1. Wiseman BS, Werb Z. Stromal effects on mammary gland development and breast cancer. Sci. 2002;296 (5570):1046-1049. doi:10.1126/science.1067431

2. Chomette G, Auriol M, Tranbaloc P, Blondon J. Stromal changes in early invasive breast carcinoma. An immunohistochemical, histoenzymological and ultrastructural study. Pathol Res Pract. 1990;186(1): 70-79. doi: https://doi.org/10.1016/S0344-0338 (11) 81 012-5

3. Bissell MJ, Radisky D. Putting tumours in context. Nat Rev Cancer. 2001;1(1): 46-54. doi:10.1038/ 350 94059

4. West RB, van de Rijn M. Experimental approaches to the study of cancer-stroma interactions: recent findings suggest a pivotal role for stroma in carcinogenesis. Laboratory Investigatio2007;87(10):967. doi: 10.1038/ labinvest.3700666.

5. Li L, Dragulev B, Zigrino P, Mauch C, Fox JW. The invasive potential of human melanoma cell lines correlates with their ability to alter fibroblast gene expression in vitro and the stromal microenvironment in vivo. Int J Cancer. 2009; 125(8):1796-1804. doi: 10. 1002/ijc. 24463.

6. Radhakrishnan VV, Aikat BK. Elastosis in breast carcinoma. Indian J Cancer. 1977;14(4):307-312.

7. Bonser GM, Dossett JA, Jull JW. Human and experimental breast cancer. Thomas; 1961.

8. Martinez-Hernandez A, Francis DJ, Silverberg SG. Elastosis and other stromal reactions in benign and malignant breast tissue. An ultrastructural study. Cancer. 1977; 40 (2): 700-706. doi: 10.1002/1097-0142 (197708)40:2<700::aid-cncr2820400217>3.0.co;2-w.

9. Mills SE, Greenson J, Hornick J, Longacre T, editors. Sternberg's Diagnostic Surgical Pathology. 6th ed. Philadelphia: Wolters Kluwer; 2015. Chapter 30, Breast; p.317-384

10. Pai MR, Pai KN, Rao RV, Naik R, Shankarnarayana, Baliga P. Connective tissue stromal changes in tumours and tumour-like lesions of the breast. Indian J Pathol Microbiol. 1999;42(3):327-332.

11.Azzopardi JG, Laurini RN.Elastosis in breast cancer. Cancer. 1974; 33(1):174-183. doi:10.1002/1097-0142 (197401)33:1<174::aid-cncr2820330126>3.0.co;2-x

12. Gaur BS, Singh R, Mishra M. Elastosis in premalignant and malignant lesions of breast- A histopathological and histochemical study. Int J Med Res Rev. 2016;4(4):668-671.doi: 10.17511/ijmrr. 2016. i04.33.

13. Barcellos-Hoff MH, Ravani SA. Irradiated mammary gland stroma promotes the expression of tumorigenic potential by unirradiated epithelial cells. Cancer Res. 2000;60(5):1254-1260.

14. Skobe M, Fusenig NE. Tumorigenic conversion of immortal human keratinocytes through stromal cell activation. Proceed Nat Acad Sci. 1998; 95(3):10501055. doi:10.1073/pnas.95.3.1050.

15. Forsberg K, Valyi-Nagy I, Heldin $\mathrm{CH}$, Herlyn $\mathrm{M}$, Westermark B. Platelet-derived growth factor (PDGF) in oncogenesis: development of a vascular connective tissue stroma in xenotransplanted human melanoma producing PDGF-BB. Proc Natl Acad Sci U S A. 1993; 90 (2): 393-397. doi: 10.1073/pnas. 90.2. 393

16. Bellini A, Mattoli S. The role of the fibrocyte, a bone marrow-derived mesenchymal progenitor, in reactive and reparative fibroses. Lab Invest. 2007; 87 (9) : 858870. Epub 2007 Jul 2. doi:10.1038/labinvest. 3700654

17. Barth PJ, Ebrahimsade S, Ramaswamy A, Moll R. CD34+ fibrocytes in invasive ductal carcinoma, ductal carcinoma in situ, and benign breast lesions. Virchows Archiv. 2002; 440(3): 298-303. doi:10.1007/s004280 100530.

18. Mori L, Bellini A, Stacey MA, Schmidt M, Mattoli S. Fibrocytes contribute to the myofibroblast population in wounded skin and originate from the bone marrow. Exp Cell Res. 2005;304(1):81-90. Epub 2004 Dec 8. doi:10.1016/j.yexcr.2004.11.011 
Original Research Article

19.Shivas AA, Douglas JG. The prognostic significance of elastosis in breast carcinoma. J R Coll Surg Edinb. 1972;17(5):315-320.

20. Fisher ER, Gregorio RM, Fisher B, Redmond C, Vellios F, Sommers SC. The pathology of invasive breast cancer. A syllabus derived from findings of the National Surgical Adjuvant Breast Project (protocol no. 4). Cancer. 1975;36(1):1-85. doi:10.1002/1097-0142 (197507) 36:1<1::aid-cncr2820360102>3.0.co;2-4

21. Anastassiades OT, Bouropoulou V, Kontogeorgos G, Tsakraklides EV. Duct elastosis in infiltrating carcinoma of the breast. Pathol Res Pract. 1979; 165 (4): 411-421. doi: https://doi.org/10.1016/S0344-0338 (79) 80033-3

22. Parfrey NA, Doyle CT. Elastosis in benign and malignant breast disease. Hum Pathol. 1985;16(7):674676. doi:10.1016/s0046-8177(85)80150-7

23. Jackson JG, Orr JW. The ducts of carcinomatous breasts, with particular reference to connectivetissue changes. J Pathol Bacteriol. 1957;74(2):265-273. doi: https://doi.org/10.1002/path.1700740203

24. Lundmark C. Breast cancer and elastosis. Cancer. 1972;30(5):1195-1201. doi:10.1002/1097-0142 (197211) 30:5<1195::aid-cncr2820300509>3.0.co;2-h
25.Douglas JG,Shivas AA. The origins of elastica in breast carcinoma.J R Coll SurgEdinb.1974;19(2):89-93.

26. Wallgren A, Silfverswärd C, Eklund G. Prognostic factors in mammary carcinoma. Acta Radiol Ther Phys Biol. 1976;15(1):1-16.

27. Mitchell RE, Mitchell RM, Shugg D, Wyld C. The prognosis of breast cancer based on histological assessment. Aust NZJ Surg. 1979;49(3):305-312. doi: https://doi.org/10.1111/j.1445-2197.1979.tb07670.x

28.Robertson AJ, Brown RA, Cree IA, MacGillivray JB, Slidders W, Beck JS. Prognostic value of measurement of elastosis in breast carcinoma. J Clinic Pathol 1981;34:738-743.doi:10.1136/jcp.34.7.738

29. Aiyer HM, Jain M, Thomas S, Logani KB. Diagnostic stromal histomorphology in fibroepithelial breast lesions: a fresh perspective. Indian $\mathrm{J}$ Pathol Microbiol. 2000;43(1):5-12.

30.Wernicke M, Piñeiro LC, Caramutti D, Dorn VG, Raffo MM, Guixa HG, et al. Breast cancer stromal myxoid changes are associated with tumor invasion and metastasis: a central role for hyaluronan. Mod Pathol. 2003; 16(2): 99-107. doi:10.1097/01.MP.0000051582. $75890.2 \mathrm{D}$

\section{How to cite this article?}

Reddy P, Sindhuja M. Histopathology of stromal changes in tumor and tumor like lesions of breast using special stains. Trop J Path Micro 2019;5(9):663-672.doi:10.17511/jopm.2019.i09.08. 